\title{
Impact of rapid socioeconomic development in China on nutritional status in children: two sides of a coin
}

\author{
Tena Niseteo ${ }^{1}$, Iva Hojsak ${ }^{1,2,3}$ \\ ${ }^{1}$ Referral Centre for Paediatric Gastroenterology and Nutrition, Children's Hospital Zagreb, Zagreb, Croatia; ${ }^{2}$ Department of Paediatrics, University \\ of Zagreb School of Medicine, Zagreb, Croatia; ${ }^{3}$ Department of Paediatrics, School of Medicine, Josip Juraj Strossmayer University of Osijek, \\ Osijek, Croatia \\ Correspondence to: Iva Hojsak, MD, PhD. Referral Centre for Paediatric Gastroenterology and Nutrition, Children's Hospital Zagreb, Klaićeva 16, \\ 10000 Zagreb, Croatia. Email: ivahojsak@gmail.com. \\ Provenance: This is an invited article commissioned by the Guest Section Editor Dr. Ying Zhao, MM (Department of Laboratory Medicine, the First \\ Affiliated Hospital, Zhejiang University School of Medicine, Hangzhou, China). \\ Comment on: Dong Y, Jan C, Ma Y, et al. Economic development and the nutritional status of Chinese school-aged children and adolescents from \\ 1995 to 2014: an analysis of five successive national surveys. Lancet Diabetes Endocrinol 2019;7:288-99.
}

Submitted Oct 15, 2019. Accepted for publication Oct 25, 2019.

doi: 10.21037/atm.2019.10.101

View this article at: http://dx.doi.org/10.21037/atm.2019.10.101

Primary malnutrition, the one caused by socioeconomic factors, is still common problem in low- and middleincome countries (LMIC). Even today, estimated world prevalence of undernutrition is $10 \%$ with the highest rate in the Eastern and Sub-Saharan Africa (30.8\%, 22.8\%, respectively) (1). Malnutrition is usually described as undernutrition or wasting [body weight under -2 standard deviation (SD)] or as chronic undernutrition or stunting (body height under -2 SD) (2). Surely, the most vulnerable population are children due to very high energy and protein requirements and low body reserves. Undernourishment in children has many devastating consequences including increased risk for infectious diseases and early death. While long lasting effects prevent children to reach their full physical and cognitive potential causing the impaired work capacity and quality of life in adulthood (3).

During the 1970-ties the prevalence of stunting among children up to 5 years old, in all developing countries, was over 50\% (54.3\%) with highest prevalence in South and East Asia and The Pacific region (68.8\%, 54.9\%, respectively) (4). During next four decades, in year 2010, the overall prevalence of pediatric malnutrition decreased to $25.1 \%$ (4). In this period there were several international initiatives as Millennium Development Goals (MDGs) choosing malnutrition as their major goal. Copenhagen Consensus from 2008 listed nutrition specific interventions five times in the top 10 priorities for international development (5). Year 2015 marked the end of the MDGs era and the beginning of the implementation of the Sustainable Development Goals with focus on reducing undernutrition among children (6).

Socioeconomic development is considered a major policy instrument for improving health and nutrition in LMIC. The basic premise is that economic growth is the pivotal for improving population health and nutrition by improving the incomes and increasing the consumption of healthpromoting goods and services $(7,8)$. Usually, socioeconomic development is measured as an increase in gross domestic product (GDP) per capita. However, this approach has often been strongly criticized for not capturing the overall wellbeing of the population. Therefore, several attempts were made to develop more appropriate indicators like the World Bank's human development index (HDI) including GDP per capita, life expectancy at birth and the adult literacy rate or Simultaneous Equation Model (SEM) including GDP, literacy rate, life expectancy and pollution indicator (9). Although, these indexes seemed to be more informative it has been shown that they highly correlate with income (economic indicators as GDP) and vice versa (10) and the bidirectional relationship between some of these indicators has been documented (9).

In the past three decades there was a remarkable surge of interest in relationship between socioeconomic growth of LMIC and nutritional status of children. As 
mentioned before, large policy initiatives aimed to improve socioeconomic growth and children nutritional status in LMIC and the results of these initiatives are shown in large number of national and international studies $(4,8,10)$. One of the largest studies investigating association between economic growth and early childhood undernutrition included 462,854 children for assessing stunting, 485,152 for assessing underweight, and 459,538 for assessing wasting in 36 different countries during the period of 22 years (form beginning of 1990 to the end of 2011) (8). This study found no significant positive effect of macroeconomic growth on early childhood stunting, underweight, and wasting. Lack of association could be at least partially explained by the unequal distribution of income growth, funds not spent in way to enhance the nutritional status of children or poor correlation between rising average incomes and improvements of the public health care services (8). On contrary, mono-national studies, although very heterogeneous (different outcome measures, methodologies, age and period used in studies) most of them gave the same conclusion clearly stating that poverty, low literacy rate, large families, food insecurity, food safety, women's education are most important underlying factors responsible for poor nutritional status (wasting and stunting) and health in children in LMIC (3,11-14).

Moreover, it seems that socioeconomic advance has a positive effect on children growth and development in most of the LMIC where, on average, annual GDP increase of $5.5 \%$ per capita reduces stunting prevalence by a full percentage point $(10,15,16)$. However, results are not equivocal and socioeconomic growth did not have the positive impact on lowering malnutrition in Indian children (7). Indicating that for some areas direct investments in health and health-related programs are needed (7).

The fact that China underwent rapid economic growth increasing the GDP from 10 trillion to almost 64 trillion $¥$ gave the possibility to Dong et al. (17) to clearly see the impact of socioeconomic growth on nutritional status of children in rural and urban areas.

Authors preformed very comprehensive study on a very large number of children and adolescents $(1,054,602)$ aged 7-18 years who took part in successive waves of the Chinese National Survey on Students' Constitution and Health across 29 provinces between 1995 and 2014. The distribution of children during this period was almost equal $(204,932$ in $1995 ; 209,167$ in $2000 ; 225,213$ in 2005; 208,136 in 2010; 207,154 in 2014) ensuring a good intergroup comparison. All children included in analysis had complete records on demographic and socioeconomic features. Nutritional status was determined by using WHO standards and classification. Socioeconomic growth was not evaluated only by using GDP, but also using Engel coefficient which describes the proportion of household spent on food (the greater the Engel coefficient the poorer the country or family) and urbanization level giving the information on proportion of people living in urban area. By using these socioeconomic indicators authors gave better insight in overall distribution of growth in incomes but also on the migration of population during long period of economic growth. Moreover, tracking the urbanization level enabled clearer answer regarding rural-urban differences.

Authors nicely showed significant association between the improvement in socioeconomic indicators and lower proportion of children who were wasted and stunted. Mean prevalence of stunting decreased form $8.1 \%$ (in 1995) to $2.4 \%$ (in 2014), and the mean wasting prevalence declined from $7.5 \%$ to $4.1 \%$. Interestingly, authors also looked at the change in prevalence of overnutrition and obesity indicating possible negative effects of socioeconomic development. There was significant increase in overweight and obesity, both in rural and urban areas, from $5.3 \%$ to $20.5 \%$, where greater increase was in rural area. Furthermore, urban-rural disparities in the prevalence of stunting, overweight and obesity diminished over time.

This rapid shift and increase in overnutrition in both rural and urban areas could cause a dual malnutrition burden, undernutrition and overnutrition in LMIC. Therefore, there is an urgent need for the investment in policies that promote healthy lifestyle and wellbeing rather than overconsumption and increased intake of unhealthy diet.

This study excluded children and adolescents who were not attending or are no longer in the school which could be a possible bias as, usually, those children could belong to the group with the lowest socioeconomic status. Furthermore, only Han Chinese children were included so extrapolation of conclusions to other ethnic groups in Chin should be done with caution. Despite these limitations, study is comprehensive including large and homogenous cohort with comprehensive evaluation of nutritional status across multiple provinces in China.

Rapid socioeconomic development in China caused significant changes in the nutritional status where positive effects, including improvements in stunting and wasting, were unfortunately followed by negative effects with increase in overweight and obesity. 


\section{Acknowledgments}

None.

\section{Footnote}

Conflicts of Interest: The authors have no conflicts of interest to declare.

Ethical Statement: The authors are accountable for all aspects of the work in ensuring that questions related to the accuracy or integrity of any part of the work are appropriately investigated and resolved.

\section{References}

1. WFP. The State of Food Security and Nutrition in the World (SOFI): Safeguarding against economic slowdowns and downturns. 2019. Available online: https://www.wfp. org/publications/2019-state-food-security-and-nutritionworld-sofi-safeguarding-against-economic

2. WHO. Management of severe malnutrition: a manual for physicians and other senior health workers. Geneva: World Health Organization, 1999.

3. Galgamuwa LS, Iddawela D, Dharmaratne SD, et al. Nutritional status and correlated socio-economic factors among preschool and school children in plantation communities, Sri Lanka. BMC Public Health 2017;17:377.

4. Smith LC, Haddad L. Reducing Child Undernutrition: Past Drivers and Priorities for the Post-MDG Era. World Dev 2015;68:180-204.

5. Copenhagen Consensus Center. Copenhagen Consensus 2008 Outcomes. Available online: https://www. copenhagenconsensus.com/copenhagen-consensus-ii/ outcomes

6. United Nations Sustainable Development. About the Sustainable Development Goals. Available online: https://www.un.org/sustainabledevelopment/sustainabledevelopment-goals/

7. Subramanyam MA, Kawachi I, Berkman LF, et al. Is

Cite this article as: Niseteo T, Hojsak I. Impact of rapid socioeconomic development in China on nutritional status in children: two sides of a coin. Ann Transl Med 2019;7(Suppl 8):S301. doi: 10.21037/atm.2019.10.101 economic growth associated with reduction in child undernutrition in India?. PLoS Med. 2011;8:e1000424.

8. Vollmer S, Harttgen K, Subramanyam MA, et al. Association between economic growth and early childhood undernutrition: evidence from 121 Demographic and Health Surveys from 36 low-income and middle-income countries. Lancet Glob Health. 2014;2:e225-34.

9. Cracolici MF, Cuffaro M, Nijkamp P. The Measurement of Economic, Social and Environmental Performance of Countries: A Novel Approach. Soc Indic Res 2010;95:339-56.

10. Headey DD. Developmental Drivers of Nutritional Change: A Cross-Country Analysis. World Dev 2013;42:76-88.

11. Adeladza A. The influence of socio-economic and nutritional characteristics on child growth in Kwale District of Kenya. AJFAND 2010;9:1570-90.

12. Kamiya Y. Socioeconomic determinants of nutritional status of children in Lao PDR: effects of household and community factors. J Health Popul Nutr 2011;29:339-48.

13. Kanjilal B, Mazumdar PG, Mukherjee M, Rahman MH. Nutritional status of children in India: household socioeconomic condition as the contextual determinant. Int J Equity Health 2010;9:19.

14. Babar NF, Muzaffar R, Khan MA, et al. Impact of socioeconomic factors on nutritional status in primary school children. J Ayub Med Coll Abbottabad 2010;22:15-8.

15. Biadgilign S, Shumetie A, Yesigat H. Does Economic Growth Reduce Childhood Undernutrition in Ethiopia?. PLoS One 2016;11:e0160050.

16. Wu L, Yang Z, Yin SA, et al. The relationship between socioeconomic development and malnutrition in children younger than 5 years in China during the period 1990 to 2010. Asia Pac J Clin Nutr 2015;24:665-73.

17. Dong Y, Jan C, Ma Y, et al. Economic development and the nutritional status of Chinese school-aged children and adolescents from 1995 to 2014: an analysis of five successive national surveys. Lancet Diabetes Endocrinol 2019;7:288-99. 